\title{
Fish bone ingestion presenting to a local institution in Singapore
}

\author{
Sabrina $\underline{\text { Cheok }}{ }^{1}$, MBBS, MRCSI, Malcolm Han Wen $\underline{M a k}^{1}$, MBBS, MRCSEd, Singh Dinesh $\underline{\text { Rambachan }}{ }^{2}$, MBBS, FRCR, \\ Clement Luck Khng $\underline{\text { Chia }}^{1}$, MBBS, FRCSEd
}

\section{INTRODUCTION}

Fish bones are the most commonly ingested foreign bodies in Singapore, accounting for up to $83.9 \%$ of ingested foreign bodies. ${ }^{(1)}$ The use of chopsticks to consume fish, the personal habit of deboning fish in the mouth and denture usage in the elderly have been described as risk factors for the ingestion of fish bones. ${ }^{(2)}$

The first line of investigation after ingestion of fish bones would include plain radiography, but this was shown to have poor sensitivity of $23.5 \%-54.8 \%{ }^{(3-5)}$ and false negative rates of up to $40 \%$. ${ }^{(6)}$ An alternative radiological modality would be the barium study, but it is limited by its false negative rate of $40 \%-50 \% .{ }^{(7)}$ Furthermore, barium contamination can render subsequent examination and removal of the ingested fish bone more technically challenging. Therefore, the current gold standard radiological modality for diagnosis is fine-cut computed tomography (CT), which not only confirms the diagnosis and reveals associated complications but also boasts a superior sensitivity of $90.9 \%-100 \%{ }^{(4,5,8)}$ One should, however, note the caveat that the use of oral or intravenous contrast during CT can obscure the presence of a fish bone. ${ }^{(8,9)}$ Hence, for a patient with a high index of suspicion for fish bone ingestion, the ordering clinician should specifically communicate with the radiologist on the indication as well as the need for a noncontrast scan.

After the diagnosis of fish bone ingestion, endoscopic removal using laryngoscopy or oesophagogastroduodenoscopy (OGD) is usually sufficient in most cases, with surgery only required in less than $1 \%$ of patients. We herein present a series of patients who ingested fish bones and presented to a local tertiary hospital in Singapore, discussing the associated complications based on the location in the gastrointestinal tract where the bones were impacted.

\section{UPPER GASTROINTESTINAL TRACT}

The majority of ingested fish bones lodge in the upper gastrointestinal tract, most commonly in the oral cavity or pharynx. ${ }^{(10)}$ A careful clinical examination of the oropharynx is required, followed by plain lateral neck radiography. Visualisation of fish bones is often challenging on plain radiography, with fish bones presenting as faint linear calcifications (Fig. 1a). In the presence of any doubt,
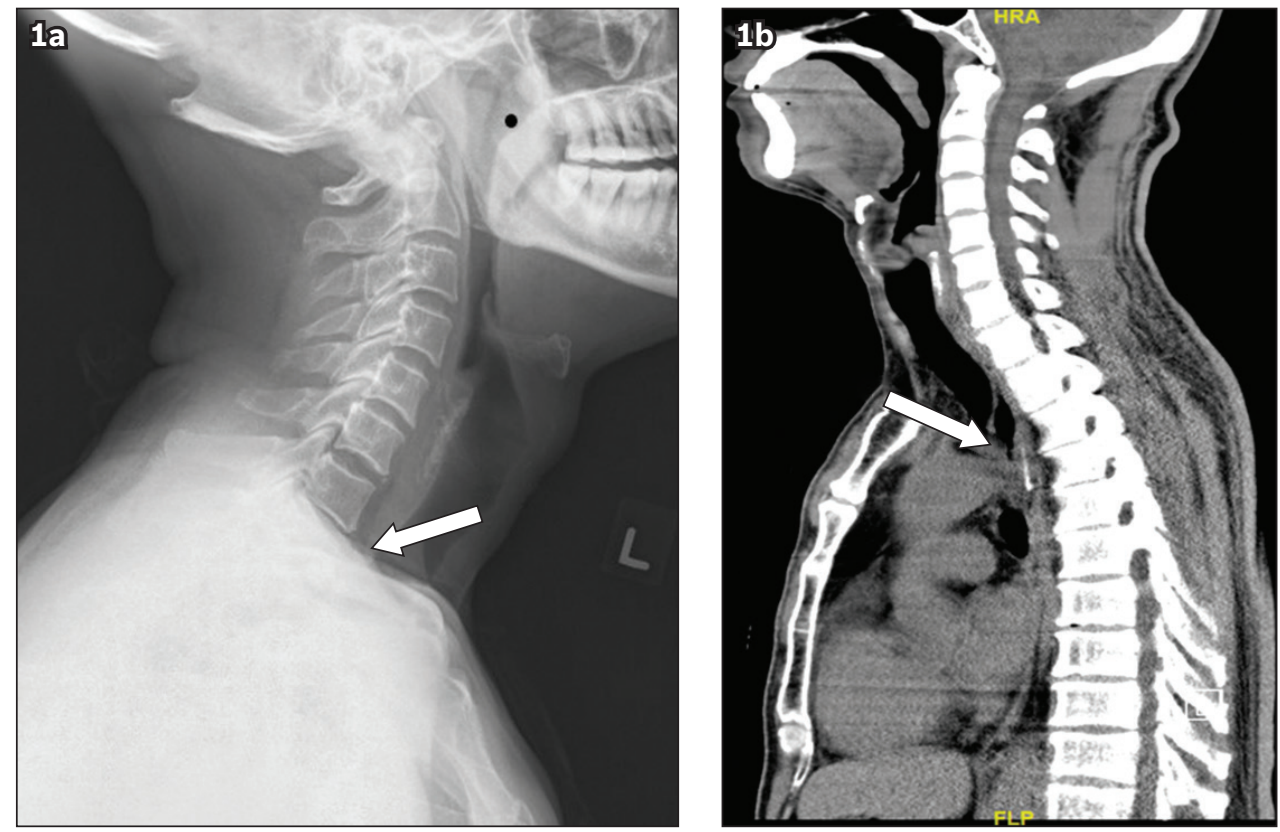

Fig. 1 (a) Plain radiograph shows a faint linear calcification suspicious of an ingested fish bone (arrow). (b) CT image of the same patient shows a linear opacity corresponding to the history of fish bone ingestion. The presence of extraluminal gas (arrow) posterior to the trachea also raises the suspicion of a localised perforation that was not detected on plain radiography.

'Department of General Surgery, ${ }^{2}$ Department of Diagnostic Radiology, Khoo Teck Puat Hospital, Singapore

Correspondence: Dr Clement Chia Luck Khng, Consultant, Department of General Surgery, Khoo Teck Puat Hospital, 90 Yishun Central, Singapore 768828. chia.clement.lk@ktph.com.sg 

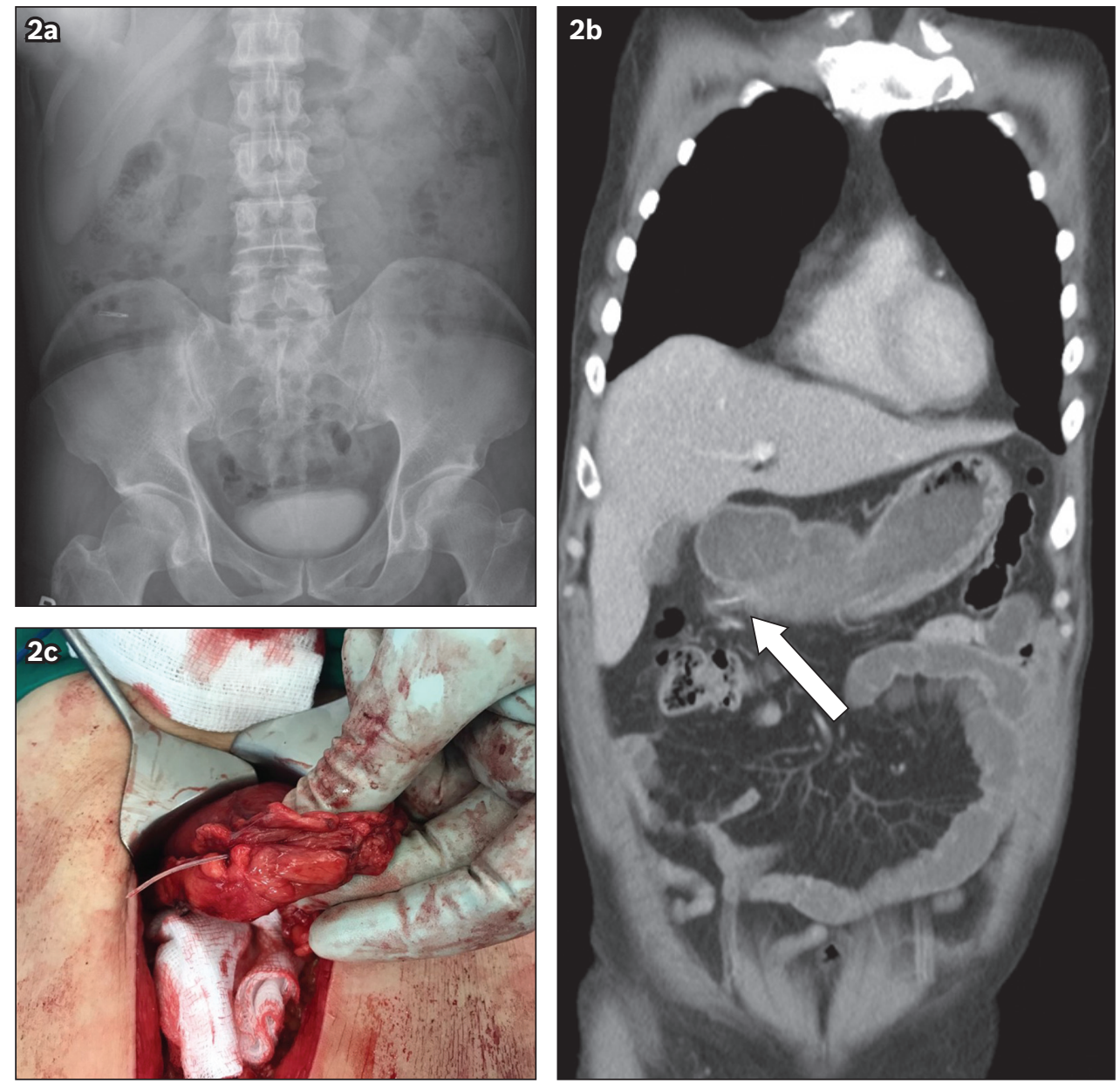

Fig. 2 (a) Abdominal radiograph shows a polypectomy clip seen in the right iliac fossa, with no other foreign body seen. (b) CT image of the abdomen shows a 3.2-cm curvilinear density that extends beyond the posterior wall of the gastric antrum (arrow), suggesting a perforation. (c) Photograph shows an exploratory laparotomy that confirmed fish bone perforation of the gastric antrum.
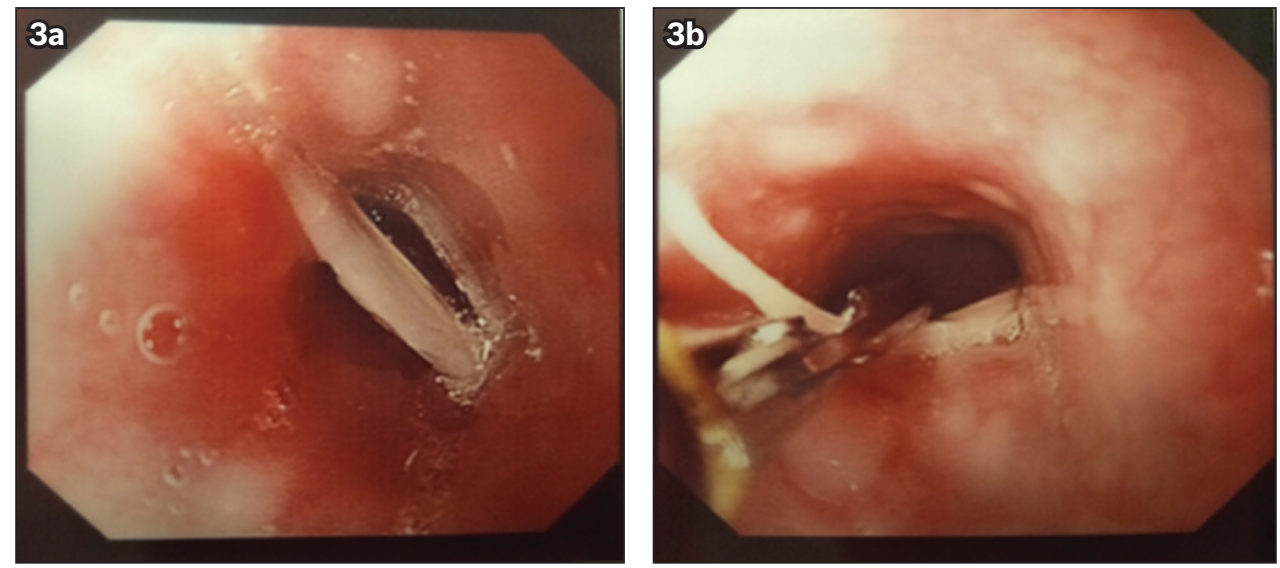

Fig. 3 (a) Oesophagogastroduodenoscopy image shows a fish bone lodged in the mid-oesophagus. (b) Endoscopy image shows the fish bone being retrieved using a pair of rat-tooth forceps.

subsequent CT (Fig. 1b) should be performed, especially in a symptomatic patient with a recent history of fish bone ingestion. Fig. 2 highlights another patient where the superior sensitivity of CT compared to plain radiography in detecting fish bones is demonstrated.

Removal by endoscope should be attempted for any ingested fish bone that is detected proximal to the jejunum and can be reached via endoscopy. This is in view of the potential for serious complications, such as perforation of the oesophagus and the stomach that may result in abscess formation or adjacent vascular injury. ${ }^{(11)}$ Retrieval options include direct laryngoscopy, rigid oesophagoscopy or flexible OGD, depending on the location where the fish bone is impacted. Fig. 3 shows endoscopic confirmation of an ingested fish bone impacted in the mid-oesophagus, which was subsequently removed. 

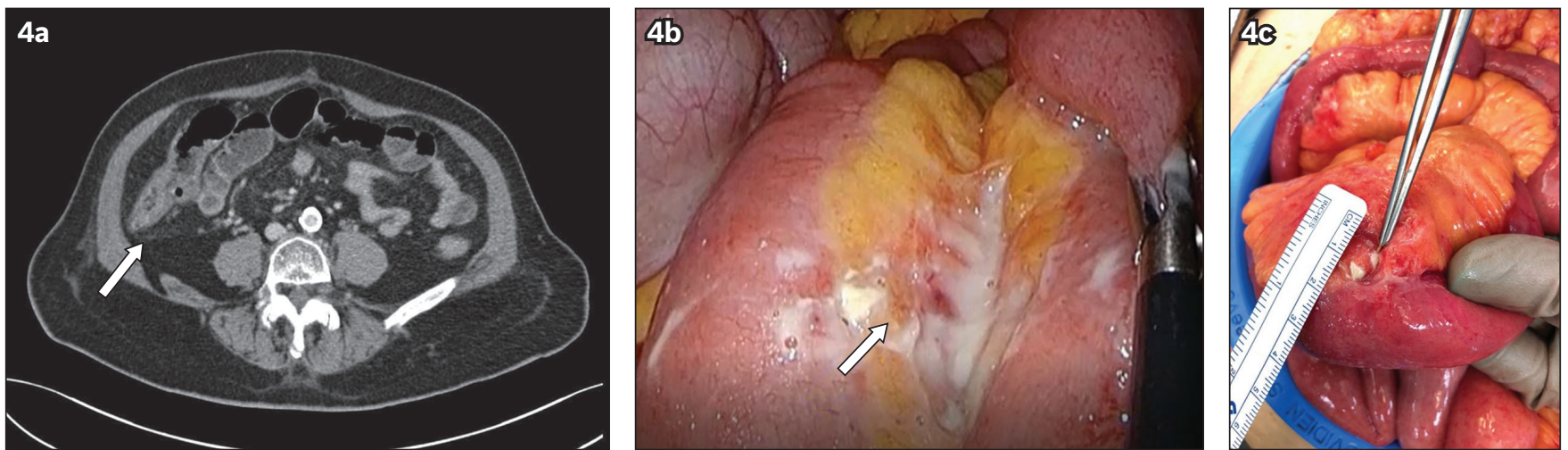

Fig. 4 A 52-year-old man presented with acute abdomen of one day's duration, with no recollection of fish bone ingestion. (a) CT image of the abdomen shows non-specific stranding at the proximal ascending colon without any evidence of a foreign body (arrow). (b) Subsequent diagnostic laparoscopy shows interloop jejunal adhesions with purulent discharge (arrow). No perforation could be visualised on laparoscopy. (c) Laparotomy was subsequently performed as an aetiology was not identified on diagnostic laparoscopy. Photograph shows a 3-cm fish bone that perforated the mid-jejunum and was lodged in the mesentery.
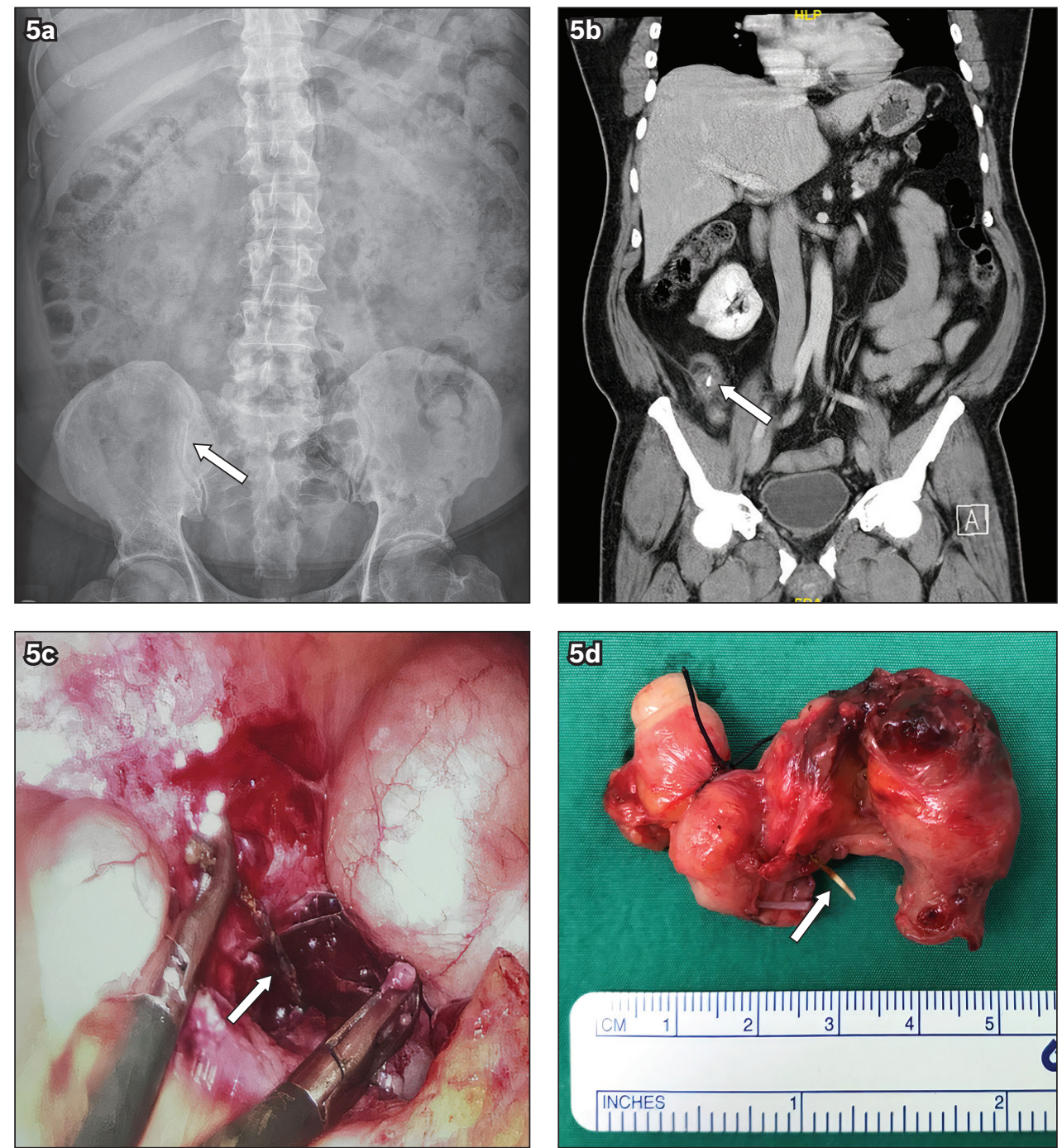

Fig. 5 A 35-year-old man presented with right iliac fossa pain and fever. (a) Abdominal radiograph shows a curvilinear opacity projected over the right iliac fossa (arrow). (b) CT image shows acute appendicitis with a linear foreign body within the appendix lumen (arrow). (c) Diagnostic laparoscopy image shows a fish bone (arrow) penetrating through the posterior wall of appendix with localised abscess in the right iliac fossa identified. (d) Photograph shows the appendiceal specimen with the fish bone (arrow) lodged in the mid body.

\section{SMALL BOWEL AND LOWER}

\section{GASTROINTESTINAL TRACT}

These patients are usually asymptomatic and present to the hospital only when complications occur. Most patients may even be oblivious to their history of recent fish bone ingestion, ${ }^{(12)}$ and detection is usually made on $\mathrm{CT}$ performed to investigate abdominal pain. Similarly, the detection of fish bones in this part of the gastrointestinal tract with plain radiography is limited, as the 

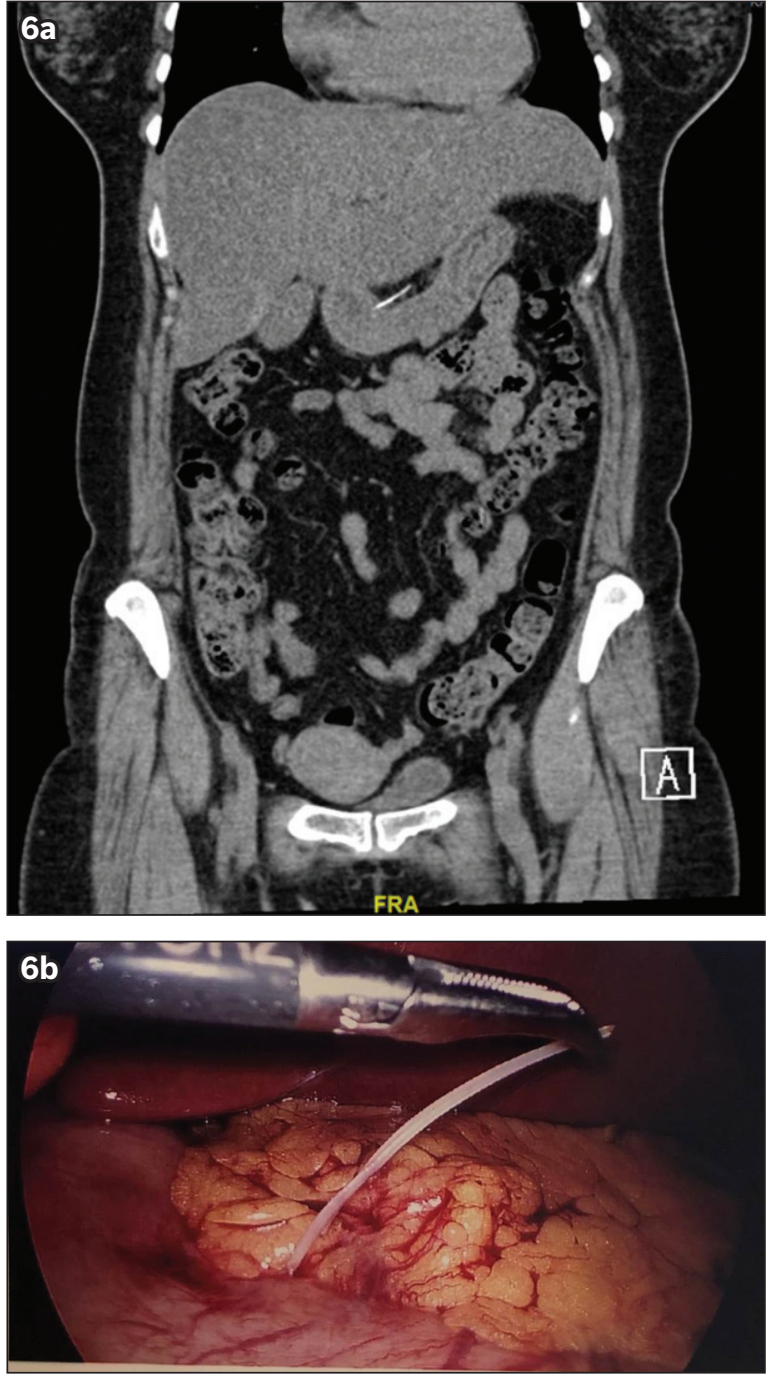

Fig. 6 A 65-year-old man presented with a history of fish bone ingestion and epigastric pain. (a) CT image shows a $2.1-\mathrm{cm}$ linear density traversing the pyloric end of the stomach. (b) Laparoscopy image shows the removal of fish bone perforating stomach pylorus. The patient subsequently underwent omental patch repair of the site of perforation.

majority of fish bones are radiolucent and obscured by the fluid and soft tissue of the abdomen. ${ }^{(13)}$ Fig. 4 illustrates the case of a patient with jejunal perforation who presented with abdominal pain and had no recollection of fish bone ingestion.

\section{COMPLICATIONS}

Most ingested fish bones pass through the gastrointestinal tract uneventfully. However, the sharp edges of fish bones predispose the patient to serious complications such as perforation, migration and consequent infection when the fish bone is impacted in adjacent organs.

The most common complication, hollow viscus perforation, tends to occur at immobile segments of the gastrointestinal tract such as the ileocecal or rectosigmoid junction. ${ }^{(14)}$ Unusual sites of perforation through a Meckel's diverticulum or even the appendix (Fig. 5) have also been reported. ${ }^{(15)}$ Common radiological manifestations on $\mathrm{CT}$ include localised collections, fat stranding, bowel thickening or direct visualisation of calcified fish bone.
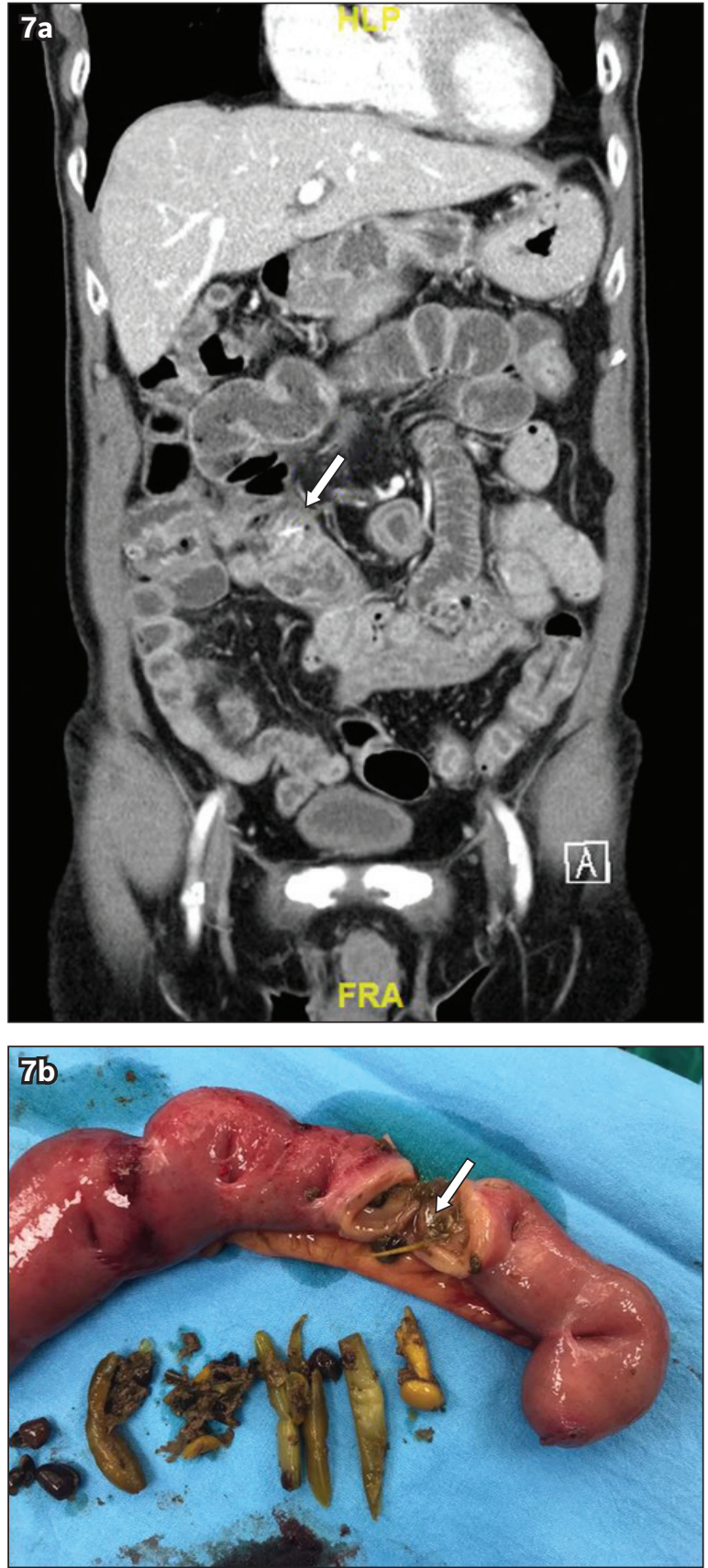

Fig. 7 A 70-year-old man with a history of descending colon cancer and open left hemicolectomy presented with three days of abdominal pain and guarding. (a) CT image shows a linear hyperdensity coupled with fat stranding and bowel thickening suggestive of a lodged fish bone (arrow). (b) Photograph shows the fish bone (arrow) that was identified following exploratory laparotomy and small bowel resection at the site of the perforation. Multiple adhesions along segment of resected bowel could explain why the fish bone was trapped at a point of narrowing, resulting in the perforation.

The presence of extensive pneumoperitoneum is rare $^{(14)}$ due to the small calibre of fish bones.

Surgical intervention is almost certainly required in the event of perforation. The option of laparoscopic retrieval (Fig. 6) can be attempted in a patient who is haemodynamically stable with localised tenderness, with a low threshold for conversion to a laparotomy (Fig. 7) if the location of the perforation is not identified. 

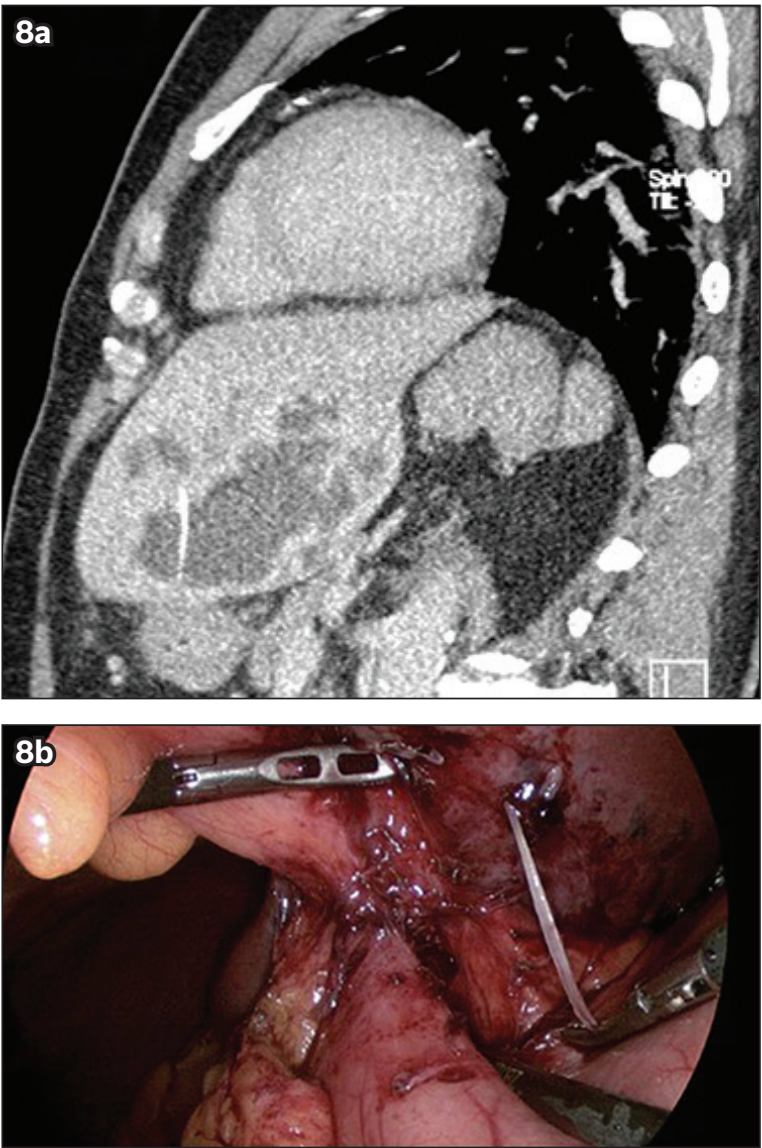

Fig. 8 A 72-year-old man presented with a two-week history of fever chills and diarrhoea. (a) CT image of the abdomen shows left hepatic liver abscess with linear density seen within the abscess cavity, likely representing a fish bone. (b) Diagnostic laparoscopy image shows the fish bone impacted on the undersurface of the left lobe of the liver; it was retrieved laparoscopically.

Another unusual complication would be the development of liver abscess (Fig. 8) adjacent to the site of bowel perforation. The principles of source control by removal of the foreign body and repairing the site of perforation would similarly apply to this situation. Additional drainage of liver abscess may also be required for complete resolution.

\section{CONCLUSION}

A high index of suspicion is required for a symptomatic patient with a recent history of fish consumption. CT should be performed even in the absence of radiographic findings due to its superior sensitivity in detecting fish bones. When complications of perforation occur, surgical options can include laparoscopy but with a low threshold for laparotomy to remove the foreign body and repair the site of perforation.

\section{REFERENCES}

1. Lim CT, Quah RF, Loh LE. A prospective study of ingested foreign bodies in Singapore. Arch Otolaryngol Head Neck Surg 1994; 120:96-101.

2. Arulanandam S, Das De S, Kanagalingam J. A prospective study of epidemiological risk factors for ingestion of fish bones in Singapore. Singapore Med J 2015; 56:329-33.

3. Evans MR, Ahuja A, Rhys Williams S, Van Hasselt CA. The lateral neck radiograph in suspected impacted fish bones--does it have a role? Clin Radiol 1992; 46:121-3.

4. Watanabe K, Kikuchi T, Katori Y, et al. The usefulness of computed tomography in the diagnosis of impacted fish bones in the oesophagus. J Laryngol Otol 1998; 112:360-4.

5. Akazawa Y, Watanabe S, Nobukiyo S, et al. The management of possible fishbone ingestion. Auris Nasus Larynx 2004; 31:413-6.

6. Derowe A, Ophir D. Negative findings of esophagoscopy for suspected foreign bodies. Am J Otolaryngol 1994; 15:41-5.

7. Herranz-Gonzalez J, Martinez-Vidal J, Garcia-Sarandeses A, Vazquez-Barro C. Esophageal foreign bodies in adults. Otolaryngol Head Neck Surg 1991; 105:649-54.

8. Goh BK, Tan YM, Lin SE, et al. CT in the preoperative diagnosis of fish bone perforation of the gastrointestinal tract. AJR Am J Roentgenol 2006; 187:710-4.

9. Bathla G, Teo LL, Dhanda S. Pictorial essay: complications of a swallowed fish bone. Indian J Radiol Imaging 2011; 21:63-8.

10. Kim JP, Kwon OJ, Shim HS, et al. Analysis of clinical feature and management of fish bone ingestion of upper gastrointestinal tract. Clin Exp Otorhinolaryngol 2015; 8:261-7.

11. Johari $\mathrm{HH}$, Khaw BL, Yusof Z, Mohamad I. Migrating fish bone piercing the common carotid artery, thyroid gland and causing deep neck abscess. World J Clin Cases 2016; 4:375-9.

12. Hsu SD, Chan DC, Liu YC. Small-bowel perforation caused by fish bone. World J Gastroenterol 2005; 11:1884-5.

13. Venkatesh $\mathrm{SH}$, Karaddi NK. CT findings of accidental fish bone ingestion and its complications. Diagn Interv Radiol 2016; 22:156-60.

14. Pinero Madrona A, Fernández Hernández JA, Carrasco Prats $M$, Riquelme Riquelme J, Parilla Paricio P. Intestinal perforation by foreign bodies. Eur J Surg 2000; 166:307-9.

15. Beh JC, Uppaluri AS, Koh BF, Cheow PC. Fishbone perforated appendicitis. J Radiol Case Rep 2016; 10:14-22. 


\section{SINGAPORE MEDICAL COUNCIL CATEGORY 3B CME PROGRAMME} (Code SMJ 202011B)

Question 1. Regarding fish bone ingestion:

(a) Cultural and personal habits such as the use of chopsticks or deboning fish in the mouth are known risk factors for fish bone ingestion.

(b) Fish bones are one of the most commonly ingested foreign bodies.

(c) Fish bone ingestion is always symptomatic.

(d) Most fish bones require surgical removal.

Question 2. Regarding imaging for fish bone ingestion:

(a) Computed tomography (CT) has superior sensitivity compared to plain radiography.

(b) Fish bone can present as linear calcification on plain radiography.

(c) Contrast should be requested for CT when fish bone ingestion is suspected.

(d) CT is superior to plain radiography in detecting complications associated with fish bone ingestion.

Question 3. Regarding fish bone ingestion in the upper gastrointestinal tract:

(a) Fish bones are most commonly lodged in the oral cavity or pharynx.

(b) Fish bones lodged in the oropharynx first require a careful clinical examination, followed by imaging.

(c) Fish bones in the upper gastrointestinal tract should be left alone.

(d) Options for removal of fish bone include direct laryngoscopy and oesophagogastroduodenoscopy.

Question 4. Regarding fish bone ingestion in the lower gastrointestinal tract

(a) Such patients are often asymptomatic unless complications related to fish bone ingestion occur.

(b) Radiography has good sensitivity in detecting fish bone in the lower gastrointestinal tract.

(c) Fish bones can lodge in rare locations such as the appendix.

(d) Fish bones in this location should be removed by endoscopy.

Question 5. Regarding complications related to fish bone ingestion:

(a) Laparoscopy is a feasible option for retrieving fish bone that is causing perforation of hollow viscus in the stable patient.

(b) Fish bone ingestion can result in liver abscess.

(c) Fish bone causing hollow viscus perforation almost always requires surgery.

(d) The objective of surgery for fish bone perforation of hollow viscus is to remove the foreign body and repair the site of perforation.

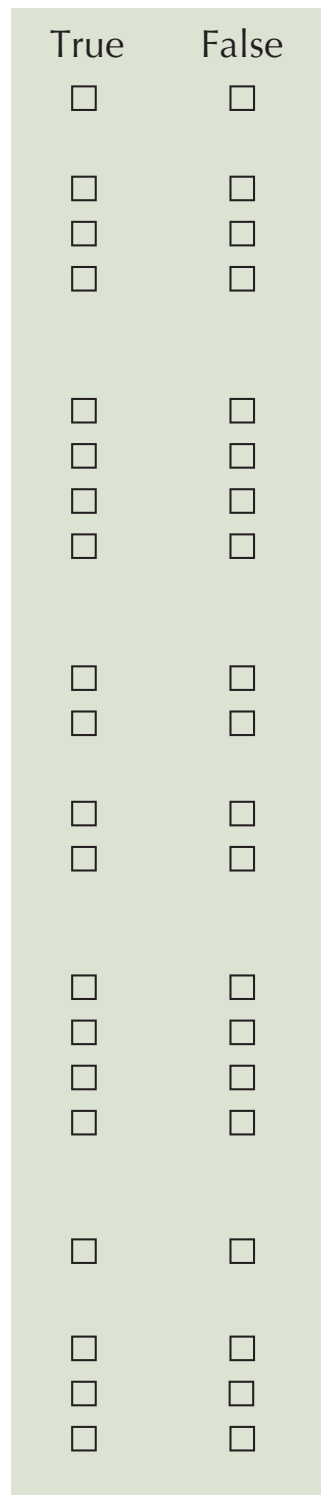

\section{Doctor's particulars:}

Name in full:

Specialty:

MCR no.:

Email:

\section{SUBMISSION INSTRUCTIONS:}

Visit the SMJ website: http://www.smj.org.sg/current-issue and select the appropriate quiz. You will be redirected to the SMA login page.

For SMA member: (1) Log in with your username and password (if you do not know your password, please click on 'Forgot your password?'). (2) Select your answers for each quiz and click 'Submit'.

For non-SMA member: (1) Create an SMJ CME account, or log in with your SMJ CME username and password (for returning users). (2) Make payment of SGD 21.40 (inclusive of $7 \%$ GST) via PayPal to access this month's quizzes. (3) Select your answers for each quiz and click 'Submit'.

RESULTS:

(1) Answers will be published online in the SMJ January 2021 issue. (2) The MCR numbers of successful candidates will be posted online at the SMJ website by 11 January 2021. (3) Passing mark is $60 \%$. No mark will be deducted for incorrect answers. (4) The SMJ editorial office will submit the list of successful candidates to the Singapore Medical Council. (5) One CME point is awarded for successful candidates. (6) SMC credits CME points according to the month of publication of the CME article (i.e. points awarded for a quiz published in the November 2020 issue will be credited for the month of November 2020, even if the deadline is in January 2021).

Deadline for submission (November 2020 SMJ 3B CME programme): 12 noon, 4 January 2021. 